\title{
Surface Analysis of Inhibitor Film Formed by Poly(Vinyl Alcohol) on Stainless Steel in Sodium Chloride Solution
}

\author{
A. Samide, ${ }^{1, *}$ A. Ciuciu, ${ }^{1}$ C. Negrila ${ }^{2}$ \\ ${ }^{1}$ University of Craiova, Faculty of Chemistry, Calea Bucuresti 107i, Craiova, Romania \\ ${ }^{2}$ National Institute of Materials Physics, 077125 Magurele-Bucharest, Romania
}

Received 4 May 2010; accepted 4 June 2010

\begin{abstract}
The corrosion inhibition of stainless steel in $0.9 \% \mathrm{NaCl}$ solution in presence of poly(vinyl alcohol) (PVA) is discussed according to electrochemical measurements, such as potentiodynamic polarization and electrochemical impedance spectroscopy (EIS).The morphology of the surface was analyzed using Scanning Electron Microscopy (SEM). The composition of the layer formed on stainless steel surface was estimated using X-ray Photoelectron Spectroscopy (XPS) technique. Electrochemical measurements indicated that the presence of PVA in $\mathrm{NaCl}$ solution decreases the corrosion current and increases the polarization resistance. The values of inhibition efficiency obtained from polarization curves and EIS measurements are in good agreement. In absence and in presence of PVA, SEM images showed that the stainless steel surface was covered with a non-uniform layer and a uniform adsorbed film, respectively. XPS analysis indicated that the surface layer consists of PVA containing a small amount of other elements, such as $\mathrm{Na}$ and $\mathrm{Cl}$.
\end{abstract}

Keywords: stainless steel; surface analysis; electrochemical measurements; SEM; XPS..

\section{Introduction}

Stainless steel is used for a wide variety of home and commercial applications; this is one of the most familiar and most frequently used alloys. 304L stainless steel offers good mechanical and corrosion properties, as well as oxidation resistance. Nevertheless, its use is limited due to its susceptibility to some types of local corrosion attack, such as pitting and stress corrosion in the presence of $\mathrm{Cl}^{-}$ions $[1,2]$.

\footnotetext{
*Corresponding author. E-mail address: samide_adriana@yahoo.com
} 
The surface roughness texture and localized corrosion resistance are the most important characteristics for stabilizing stainless steel / medium interface. Such an inconvenience can be surpassed by covering the metallic substrate with polymer coatings. The use of polymers as corrosion inhibitors has attracted considerable attention. Polymers such as poly(vinyl pyrolidone), poly ethylenimine, polyaniline and polysiloxane, and polyethylene glycol methyl ether, have been widely reported [3-10]. The application of water soluble polymers as corrosion inhibitors of metals in different media has been cited. The inhibition efficiency of poly(vinyl alcohol) in controlling the corrosion of carbon steel was investigated [11-13]. The corrosion inhibition of aluminum in $\mathrm{NaOH}$ and $\mathrm{H}_{2} \mathrm{SO}_{4}$ in the presence of poly(vinyl alcohol) as inhibitor, was studied using gravimetric, gasometric, and thermometric techniques. The inhibition efficiency increased with increase in concentration of the inhibitor [14, 15]. The inhibitors such as poly(vinyl alcohol) and polyethylene glycol were found to obey Temkin, Freundlich and Frumkin adsorption isotherms from the fit of the experimental data [14-16]. The phenomenon of physical adsorption was proposed from the activation parameters obtained.

In this regard, the surface properties of materials modified using PVA are important. By surface modification of stainless steel, we followed two objectives: to increase the corrosion resistance, knowing the fact that materials manufactured from such steel present a certain degree of leaching which leads to expelling extremely toxic chromium ions into the medium, and to prepare the surface such as to be proper for stabilizing stainless steel / medium interface.

This study discusses the results of characterization techniques such as electrochemical measurements, SEM and XPS surface analysis for behaviour of stainless steel in sodium chloride solution. The findings may be useful in saline water systems in industries under simulated conditions.

\section{Experimental}

\section{Electrochemical measurements}

For electrochemical measurements a standard cell has been used with a plate working electrode (surface area $1 \mathrm{~cm}^{2}$ ) made of stainless steel, a platinum auxiliary electrode (surface area $1 \mathrm{~cm}^{2}$ ) and $\mathrm{Ag} / \mathrm{AgCl}$ as reference electrode. The electrode made of stainless steel was polished with metallographic paper, washed in distilled water, degreased in acetone and dried in warm air. Chemical composition of $304 \mathrm{~L}$ stainless steel employed in this study is (wt\%): $\mathrm{Cr} 18-20$; Ni 8-12; Mn 2; P 0.045; C 0.03; Si 0.75; S 0.03 and Fe balance. For each determination the samples were introduced during 30 minutes, in the open circuit, at room temperature, in following solutions: sodium chloride (wt\% $0.9 \% \mathrm{NaCl} ; \mathrm{pH}=5.5) ; 0.9 \% \mathrm{NaCl} / 1 \% \mathrm{PVA} ; 0.9 \% \mathrm{NaCl} / 2 \% \mathrm{PVA} ; 0.9 \% \mathrm{NaCl} /$ $3 \%$ PVA (molecular weight of PVA was $49000 \mathrm{~g} \cdot \mathrm{mol}^{-1}$ ). All reagents were obtained from Fluka. A potentiostat VoltaLab 40 connected to a computer with VoltaMaster 4 software was used in the measurements. 


\section{Surface characterization}

SEM were accomplished using a Scanning Electron Microscope Jeol JSM 35-CF, resolution 60 Angstroms, magnification range: $10 \mathrm{X}$ - $180000 \mathrm{X}$, SE detector.

XPS spectra were recorded in a VG ESCA 3 Mk II- EUROSCAN spectrometer with a $\mathrm{Mg} \mathrm{K} \alpha \mathrm{X}$-ray source (1253.6 eV photons energy) operated at $300 \mathrm{~W}$ (accelerating voltage $12.5 \mathrm{kV}$, emission current $24 \mathrm{~mA}$ ). The pressure in the analysis chamber has not exceed the value of $5 \times 10^{-9}$ torr during the all period of spectra acquisition. In order to perform the surface charge compensation, a FG40 flood gun device (Specs Gmbh - Germany), has been used, with a $0.2 \mathrm{~mA}$ electronic current at $2 \mathrm{eV}$ energy. The samples have been measured in an "as received" condition with no other surface cleanning treatment (chemical etching or $\mathrm{Ar}^{+}$ion beam bombardment) $[17,18]$. Extended spectra were recorded with a window of $1250 \mathrm{eV}$ and $100 \mathrm{eV}$ pass energy. High resolution spectra for $\mathrm{C} 1 \mathrm{~s}$ and $\mathrm{O} 1 \mathrm{~s}$ lines were recorded with a window of $15 \mathrm{eV}$ and $20 \mathrm{eV}$ pass energy, corresponding to an experimental resolution of $1.2 \mathrm{eV}$. All spectra have been deconvoluted with SDP 2.3 XPS-International software, using Gaussian profile lines for peaks fitting.

\section{Results and discussion}

The corrosion inhibition of stainless steel in sodium chloride in absence and in presence of poly(vinyl alcohol) (PVA) is discussed according to electrochemical measurements, such as potentiodynamic polarization and electrochemical impedance spectroscopy (EIS).

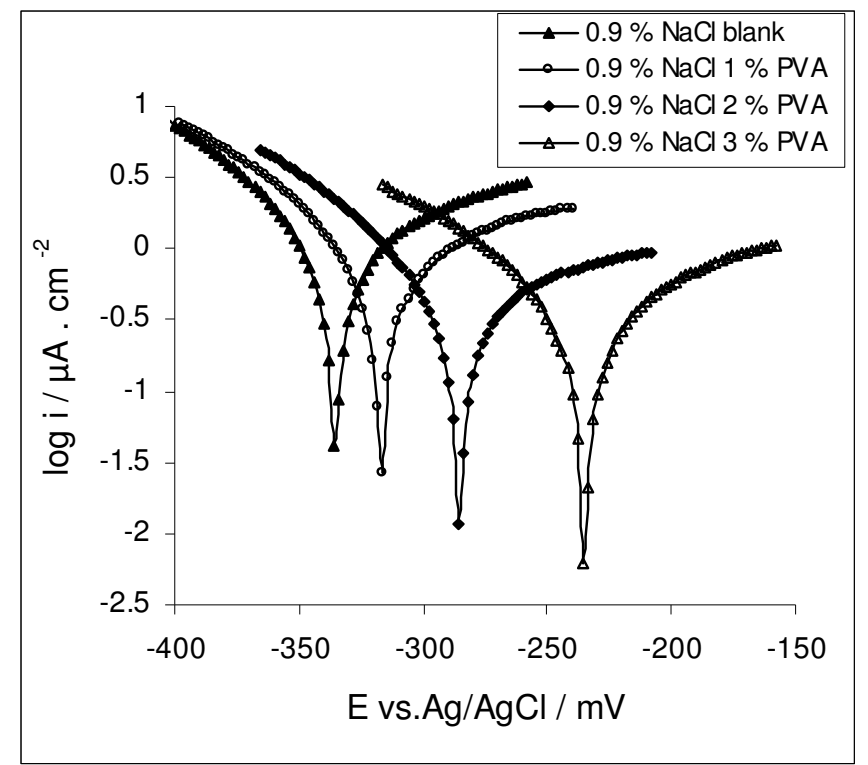

Figure 1. Polarization curves of 304L stainless steel corroded in $0.9 \% \mathrm{NaCl}$ solution in absence and in presence of different concentrations of poly(vinyl alcohol): $(1 \% ; 2 \%$; $3 \%$ ), at room temperature. 


\section{Electrochemical measurements}

\section{Polarization curves}

Polarization curves were recorded with a 304L stainless steel electrode (surface area $1 \mathrm{~cm}^{2}$ ) immersed in $0.9 \%$ sodium chloride and $0.9 \%$ sodium chloride containing different concentrations of PVA: 1\%;2\%;3\%. Fig. 1 shows the potentiodynamic curves, in the potential range of -500 to $-100 \mathrm{mV}$ vs. $\mathrm{Ag} / \mathrm{AgCl}$ reference electrode, at a scan rate of $1 \mathrm{mV} \mathrm{s}^{-1}$. The presence of PVA in the corrosive medium increases the anodic and cathodic overpotentials and decreases the corrosion current $\left(i_{\text {corr. }}\right)$. Decrease of the corrosion current was associated with an appreciable shift of corrosion potential $\left(E_{\text {corr }}\right)$ to a less negative value (Table 1).

Table1. Effect of PVA concentration on the corrosion potential $\left(\mathrm{E}_{\text {corr }}\right)$, corrosion current density ( $i_{\text {corr }}$ ), Tafel slopes $\left(b_{a}\right.$ and $b_{c}$ ), percentage inhibition efficiency (IE) of $304 \mathrm{~L}$ stainless steel in $0.9 \% \mathrm{NaCl}$ solution at room temperature.

\begin{tabular}{c|ccccccc}
\hline $\begin{array}{c}\text { C-PVA } \\
(\%)\end{array}$ & $\begin{array}{c}\mathrm{E}_{\text {corr }} \\
(\mathrm{mV} \text { vs. Ag/AgCl })\end{array}$ & $\begin{array}{c}\mathrm{i}_{\text {corr }} \\
\left.(\mu \mathrm{A} \mathrm{cm})^{-2}\right)\end{array}$ & $\begin{array}{c}\mathrm{R}_{\mathrm{p}} \\
\left(\mathrm{k} \Omega . \mathrm{cm}^{-2}\right)\end{array}$ & $\begin{array}{c}\mathrm{b}_{\mathrm{a}} \\
(\mathrm{mV})\end{array}$ & $\begin{array}{c}\mathrm{b}_{\mathrm{c}} \\
(\mathrm{mV})\end{array}$ & $\begin{array}{c}\text { Tafel } \\
\text { interpretation }\end{array}$ & $\begin{array}{c}\text { Stern-Geary } \\
\text { interpretation }\end{array}$ \\
\hline 0 & -336 & 1.78 & 1.61 & 185 & 87 & - & - \\
1 & -316 & 1.32 & 2.12 & 201 & 91 & 25.8 & 23.9 \\
2 & -286 & 0.74 & 4.28 & 192 & 76 & 58.4 & 62.4 \\
\hline 3 & -236 & 0.53 & 6.13 & 201 & 77 & 70.2 & 73.7 \\
\hline
\end{tabular}

The results showed that the corrosion current density decreased with increasing the PVA concentration, which indicates that this compound acts as an inhibitor, and the degree of inhibition depends on the concentration of inhibitor. The inhibition of 304L stainless steel in $0.9 \% \mathrm{NaCl}$ solution in the presence of PVA is due to the adsorption of the PVA on the metal surface. The slopes of the anodic and cathodic Tafel lines $\left(b_{a}, b_{c}\right)$ were slightly changed on increasing the concentration of the tested compound. The small change may be due to surface blockage by the polymer. The percentage inhibition efficiency (IE) of PVA inhibitor was also determined from polarization measurements, according to the following equation:

$$
I E=\frac{i_{c o r r}^{\prime}-i_{c o r r}}{i_{\text {corr }}^{\prime}} \times 10 \mathrm{C}
$$

where $i_{\text {corr }}$ and $i_{\text {corr }}$ are the corrosion current densities in solution without and with PVA, respectively, determined by extrapolation of Tafel lines to corrosion potential. The values of inhibition efficiency increase with PVA concentration, reaching a maximum of $70.5 \%$ at $3 \%$ PVA concentration. 


\section{Polarization resistance method}

The polarization curves obtained in the potential ranges near to corrosion potentials were recorded with a scan rate of $1 \mathrm{mV} \mathrm{s}^{-1}$. The linearization was accomplished in the domain of over-voltage values $\pm 10 \mathrm{mV}$ (Fig. 2). The slopes $(d i / d E)_{E \rightarrow E c o r r}$ of the lines from Fig. 2, represent the polarization conductance. Polarization resistance $\left(R_{p}-\mathrm{k} \Omega \mathrm{cm}^{2}\right)$ was calculated using relation 2 .

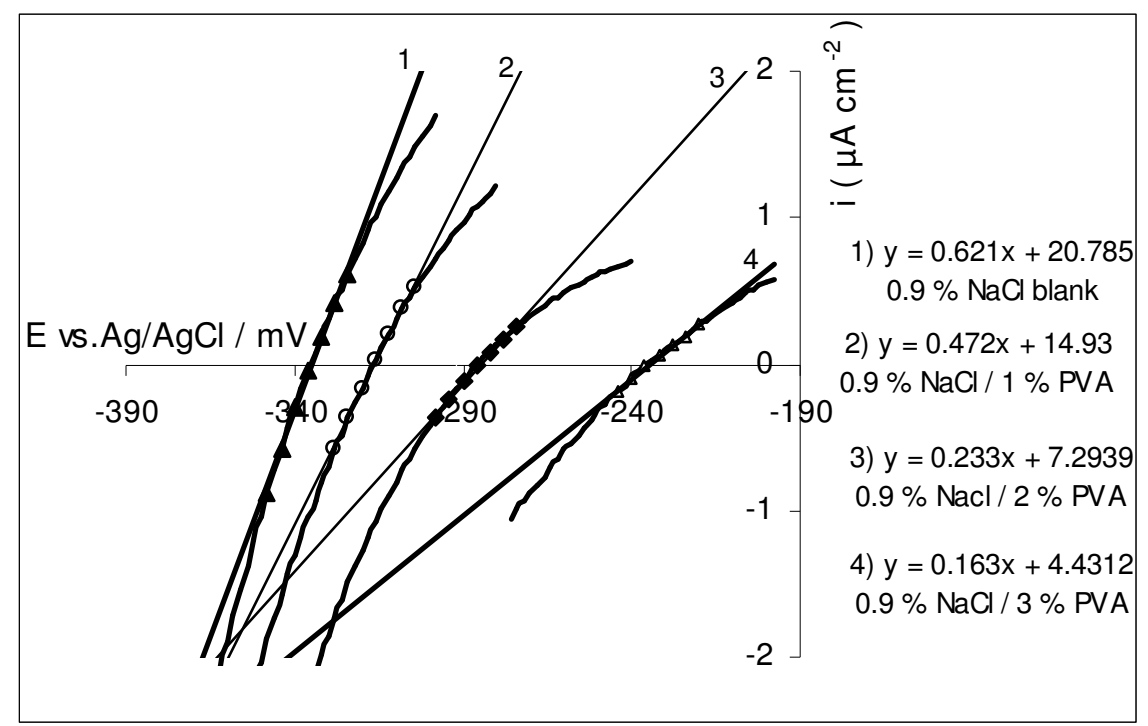

Figure 2. Polarization resistance $\left(R_{p}\right)$ of $304 \mathrm{~L}$ stainless steel corroded in $0.9 \% \mathrm{NaCl}$ solution in absence and presence of poly(vinyl alcohol) in different concentrations: $1 \% ; 2 \% ; 3 \%$.

The study of the response of stainless steel material without and with PVA given by polarizing those in $\mathrm{NaCl}$ solution, showed a shift polarization resistance $\left(R_{p}\right)$ to higher values with increasing PVA concentration (Fig. 2). This suggests that the inhibition of the stainless steel corrosion in the presence of PVA occurs by adsorption at site on the metal surface. The percentage inhibition efficiency $(I E)$ of PVA inhibitor was calculated according to the following equation:

$$
I E=\left(1-\frac{R_{p}^{0}}{R_{p}}\right) \times 100
$$

where $R_{p}^{0}$ is the polarization resistance in absence of PVA and $R_{p}$ is the polarization resistance in presence of PVA. The values of inhibition efficiency increase with PVA concentration, reaching a maximum value of $73.7 \%$ at $3 \%$ PVA concentration, nearly equal to the value obtained from Tafel polarization. The numerical values of the electrochemical parameters and of the inhibition efficiency on behaviour of stainless steel in $0.9 \% \mathrm{NaCl}$ solution and $0.9 \% \mathrm{NaCl}$ solution containing different concentrations of PVA were calculated using a VoltaMaster 4 software, with an error of $\pm 1.5 \%$, according to Stern-Geary equation (3) and are presented in Table 1. 


$$
\left(\frac{d E}{d \eta}\right)_{\eta \rightarrow 0}=\frac{b_{a} \cdot b_{c}}{2.303 i_{\text {corr }}\left(b_{a}+b_{c}\right)}
$$

where $b_{\mathrm{a}}$ and $b_{\mathrm{c}}$ are the Tafel slopes, $i_{\text {corr }}$ is the corrosion current density, and $(d E / d \eta)$ represents the polarization resistance.

\section{Electrochemical impedance measurement}

The impedance measurements of a stainless steel electrode in $0.9 \% \mathrm{NaCl}$ solution and in $0.9 \% \mathrm{NaCl}$ solution containing PVA in different concentrations vs. $\mathrm{Ag} / \mathrm{AgCl}$ reference electrode, were carried out at the corrosion potential in the frequency range from $10^{5}$ to $10^{-1} \mathrm{~Hz}$, with a value of $10 \mathrm{mV}$ for the amplitude. Fig. 3 shows the Nyquist and Bode plots for 304L stainless steel in $0.9 \% \mathrm{NaCl}$ solutions without and with PVA. It can be seen that the impedance response of stainless steel in $\mathrm{NaCl}$ solution shows a change after addition of PVA. This indicates that the impedance of stainless steel increases with the inhibitor concentration and consequently the inhibition efficiency increases. It is also apparent from these plots that the Nyquist diagram is consisted of semicircles with large diameters (extended domain for phase angle maximums in Bode diagram).
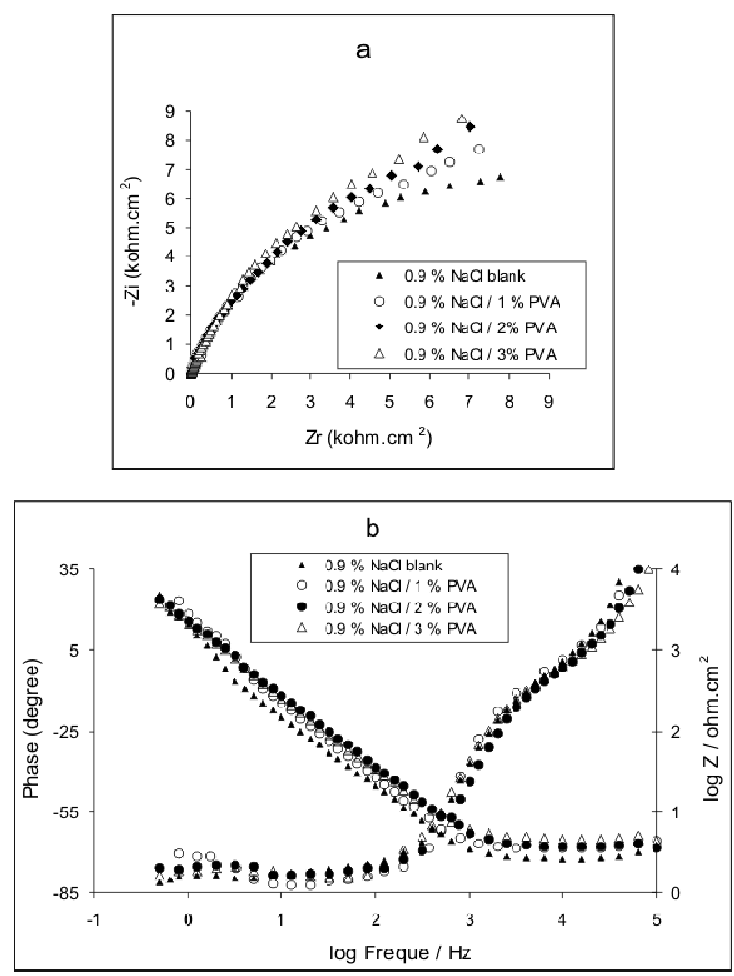

Figure 3. Electrochemical impedance measurements for 304L stainless steel in $0.9 \%$ $\mathrm{NaCl}$ solution without and with different concentrations of poly(vinyl alcohol), at room temperature: a - Nyquist plots; $b$ - Bode plots.

For the description of EIS measurements an equivalent circuit is suggested in Fig. 4, where $\left(R_{S}\right)$ is the solution resistance of the bulk electrolyte and $\left(C_{\text {coat }}\right)$ is the capacitance of the coating. $\mathrm{C}_{\text {coat }}$ is implemented as a Constant Phase Element $(\mathrm{CPE})$. If $\mathrm{C}_{\text {coat }}-\mathrm{P}$ equals 1 , the $\mathrm{C}_{\text {coat }}-\mathrm{T}$ is the simple capacitance value. $\left(R_{\text {coat }}\right)$ is 
the resistance of the coating. Coatings often have very small pores which contain electrolyte, providing a conduction path through the coating. $\left(C_{d l}\right)$ represents the double layer capacitance of the electrolyte at the metal surface. Because of heterogeneities in the coating and metal surface, this capacitance is implemented as a CPE. $\left(R_{\text {corr }}\right)$ is the corrosion resistance of the metal. The impedance parameters derived from EIS measurements and respective fitting results (e.g. stainless steel / $0.9 \mathrm{NaCl}$ solution / 2 \% PVA) are given in Table 2 and Fig.4, respectively.

The fitting results show that $R_{s}, C_{\text {coat }}-T$ and $C_{d l}-T$ decrease, and $R_{\text {coat }}$ and $R_{\text {corr }}$ increase, suggesting that the amount of inhibitor molecules absorbed increases.

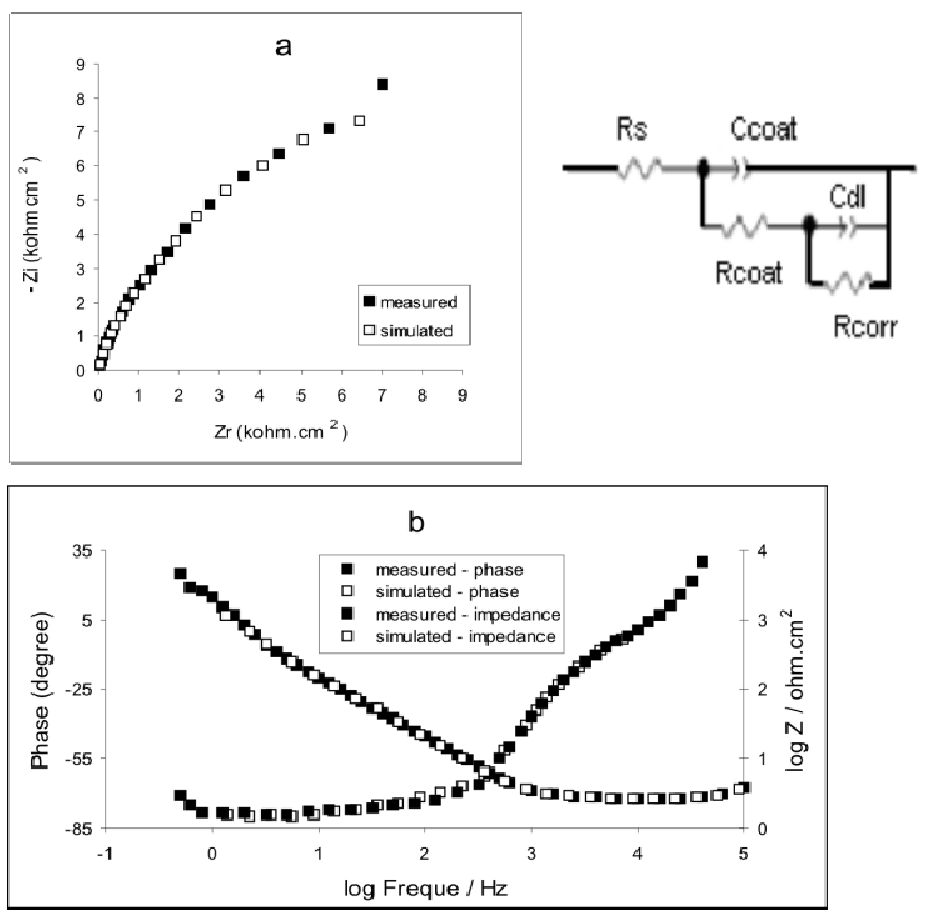

Figure 4. Equivalent circuit model for the studied inhibitor and the fit results for $304 \mathrm{~L}$ stainless steel in $0.9 \% \mathrm{NaCl}$ solution containing $2 \%$ poly(vinyl alcohol): a- Nyquist plots; b - Bode plots.

The CPE is defined by:

$$
\mathrm{Z}_{\mathrm{CPE}}=1 /\left[\mathrm{T}(\mathrm{j} \omega)^{\mathrm{P}}\right]
$$

where $\omega$ is the angular frequency and $j^{2}=-1$. When the exponent $P=1$, a CPE is identical to a capacitor and $\mathrm{T}=\mathrm{C}$. For $\mathrm{P}=0, \mathrm{a} \mathrm{CPE}$ is equivalent to a resistor and $\mathrm{T}=1 / \mathrm{R}$. At intermediate values of $\mathrm{P}$, the CPE is a phenomenological term with no simple physical justification. This decrease in $C_{c o a t}-T$ and $C_{d l}-T$ could be attributed to the decrease in local dielectric constant and/or an increase in the thickness of the electrical double layer, signifying that the PVA acts by adsorption at the interface of metal/solution. $\mathrm{P}$ values in $0.95-0.99$ domain for the $C_{\text {coat }}-P$ indicate a behavior closely related to a pure capacitor, reflecting the appropriate stimulation of the electric double layer capacity. In the same manner, values approaching to 1 of the exponent $\mathrm{P}$ of $C_{d l}-P$ for the stainless steel / $\mathrm{NaCl}$ / 3\% PVA system also indicate an important pseudo-capacity for the external 
layer, which certainly is less porous than stainless steel / $\mathrm{NaCl}$ blank solution, where $\mathrm{P}$ value of $C_{d l}-P$ is more deviated from 1 (0.83). The change in $R_{s,} R_{\text {coat }}$, $R_{\text {corr }}, C_{\text {coat }}$ and $C_{d l}$ values was caused by the gradual replacement of water molecules by adsorption of the PVA molecules on the metal surface. The $R_{\text {corr }}$ was used to calculate the inhibition efficiency from equation 5.

$$
I E=\left(1-\frac{R_{\text {corr }}{ }^{0}}{R_{\text {corr }}}\right) \times 100
$$

where $R_{\text {corr }}^{0}$ is the corrosion resistance in absence of PVA and $R_{\text {corr }}$ is the corrosion resistance in presence of PVA. The values of inhibition efficiency increase with PVA concentration, reaching an approximate value of $69 \%$ at $3 \%$ PVA concentration (Table 2). The values of inhibition efficiency obtained from Tafel polarization, resistance polarization technique and EIS measurements are in good agreement. The numerical values of $R_{s,} R_{\text {coat }}, R_{\text {corr }}, C_{\text {coat }}$ and $C_{d l}$ and of the inhibition efficiency were calculated using VoltaMaster 4 software with an error of $\pm 1 \%$, and are presented in Table 2 .

\section{Surface characterization}

The electrochemically corroded stainless steel samples by Tafel polarization in both a $0.9 \% \mathrm{NaCl}$ solution without PVA and $0.9 \% \mathrm{NaCl}$ with $3 \%$ PVA were tested by scanning electron microscopy and XPS surface analysis, and these indicate formation of superficial layer providing a very good passivation on the corroded electrode, in the presence of PVA.

Table 2. Electrochemical parameters obtained from impedance measurements for $304 \mathrm{~L}$ stainless steel in $0.9 \% \mathrm{NaCl}$ solution in absence and in presence of PVA.

\begin{tabular}{rcccccccc}
\hline $\begin{array}{l}C-P V A \\
(\%)\end{array}$ & $\begin{array}{l}R_{s} \\
\left(\Omega \mathrm{cm}^{2}\right)\end{array}$ & $\begin{array}{c}C_{\text {coat }}-T \\
\left(\mu F \mathrm{~cm}^{-2}\right)\end{array}$ & $C_{\text {coat }}-P$ & $\begin{array}{l}R_{\text {coat }} \\
\left(\Omega \mathrm{cm}^{2}\right)\end{array}$ & $\begin{array}{l}C_{d l}-T \\
\left(\mu F \mathrm{~cm}^{-2}\right)\end{array}$ & $C_{d l}-P$ & $\begin{array}{l}R_{\text {corr }} \\
\left(\Omega \mathrm{cm}^{2}\right)\end{array}$ & $\begin{array}{c}I E \\
(\%)\end{array}$ \\
\hline 0 & 2.897 & 490 & 0.95 & 258.4 & 108 & 0.83 & 2.04 & 0 \\
1 & 2.627 & 380 & 0.95 & 379.1 & 96 & 0.89 & 2.63 & 22.3 \\
2 & 1.759 & 168 & 0.97 & 539.2 & 88 & 0.95 & 4.64 & 55.9 \\
3 & 1.498 & 98 & 0.99 & 759.7 & 81 & 0.96 & 6.62 & 69.1 \\
\hline
\end{tabular}

Scanning electron microscopy

The SEM images of stainless steel surface before corrosion (Fig. 5a), and after taking place the corrosive processes in $0.9 \% \mathrm{NaCl}$ solution in absence of PVA (Fig. 5b) and in $0.9 \% \mathrm{NaCl}$ solution containing $3 \%$ PVA (Fig. 5c), are presented. It can be observed that in the absence of PVA a non-uniform layer is formed on stainless steel surface (Fig. 5b). In this regard, when the stainless steel is immersed in $0.9 \% \mathrm{NaCl}$ solution in absence of PVA, the surface layer on stainless steel is not stable and the composition can be changed by incorporation of ions and molecules. In presence of PVA the film formed on the 
stainless steel surface is different from that in the absence of PVA (Fig. 5c). The uniformity of PVA adsorbed film can be observed.

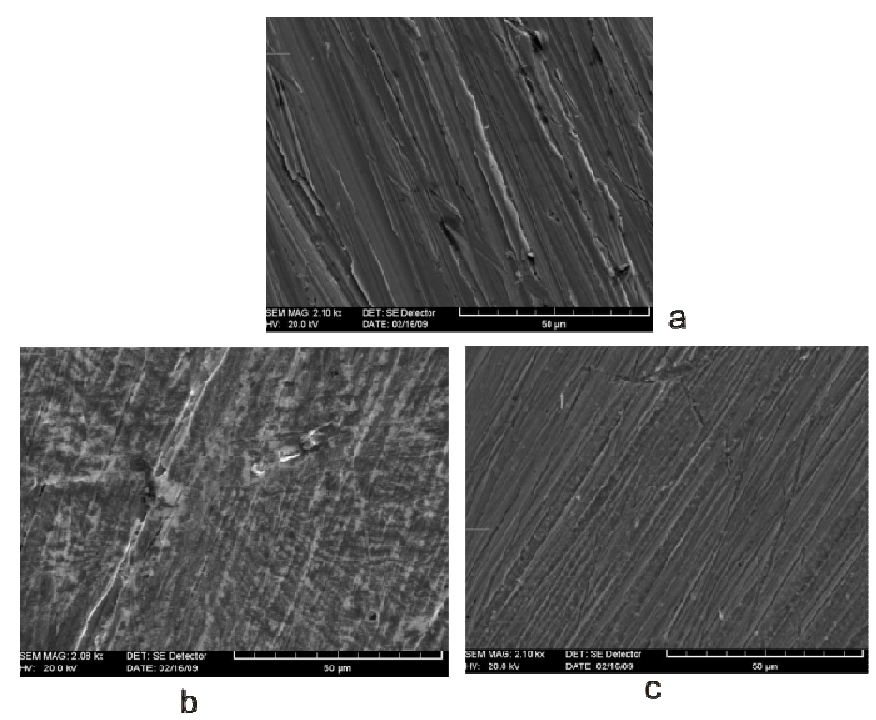

Figure 5. SEM images of stainless steel: a- before corrosion; after corrosion in: b-0.9 $\% \mathrm{NaCl}$ solution in absence of poly(vinyl alcohol); c- $0.9 \% \mathrm{NaCl}$ solution containing 3 $\%$ poly(vinyl alcohol).

\section{XPS- Surface analysis}

Surface modification techniques of stainless steel using PVA can be divided in two categories: PVA film formation and surface-modified layer composition according to PVA concentration. PVA film formation is used to improve corrosion resistance. PVA film as a whole is apparently stable, but partial destruction is taking place and, as a consequence, passive layer composition would vary with time depending on the experimental conditions. The composition of surface layer on modified stainless steel with PVA was determined using XPS surface analysis.

Extended spectrum (recorded in a $1250 \mathrm{eV}$ window) shows two large peaks at $285 \mathrm{eV}$ and $532 \mathrm{eV}$ bending energy corresponding to $\mathrm{C} 1 \mathrm{~s}$ and $\mathrm{O} 1 \mathrm{~s}$ lines. The peaks at $195.5 \mathrm{eV}$ and $1072.3 \mathrm{eV}$ correspond to $\mathrm{Na} 1 \mathrm{~s}$ and $\mathrm{Cl} 2 \mathrm{p}$ lines, respectively; quantitative evalluation from XPS extended spectrum indicates atomic concentrations for $\mathrm{Na}$ and $\mathrm{Cl}$, less than $0.5 \%$. The XPS peaks of $\mathrm{Fe}, \mathrm{Cr}$ or $\mathrm{Ni}$ (chemical composition of stainless steel substrate) are not observable in the extended spectrum (Fig. 6). This fact indicates that the substrate is completely covered.

Fig. 7 presents the high resolution XPS spectra for the $\mathrm{C} 1 \mathrm{~s}$ and $\mathrm{O} 1 \mathrm{~s}$ regions. The binding energies for the peaks have been referenced to $\mathrm{C}-\mathrm{C}$ bond at $285 \mathrm{eV}$. The binding energies of 286.51 of peak B from C1s spectra and of $532.75 \mathrm{eV}$ of peak B from O1s spectra, respectively, confirm the presence of PVA layer on the surface sample and are in good accordance with most results presented in literature [19]. The deconvolutions of spectra show the presence of -OH bonds and also of various contaminants at the surface. This confirms that PVA forms on stainless steel surface a stable and uniform layer grown from solution and the significant feature is the adsorption. 

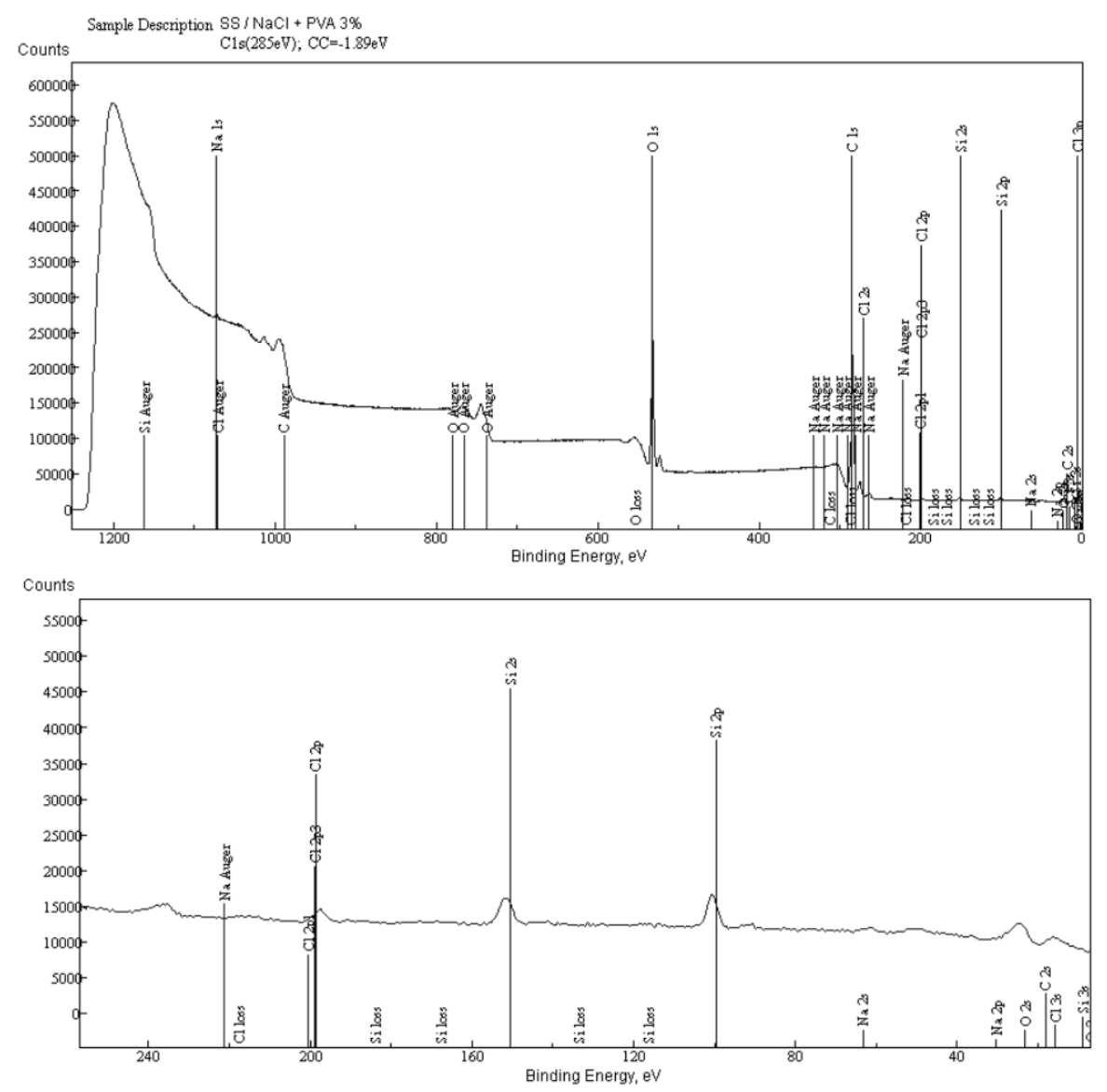

Figure 6. XPS extended spectra of stainless steel corroded in $0.9 \% \mathrm{NaCl}$ solution containing $3 \%$ poly(vinyl alcohol).
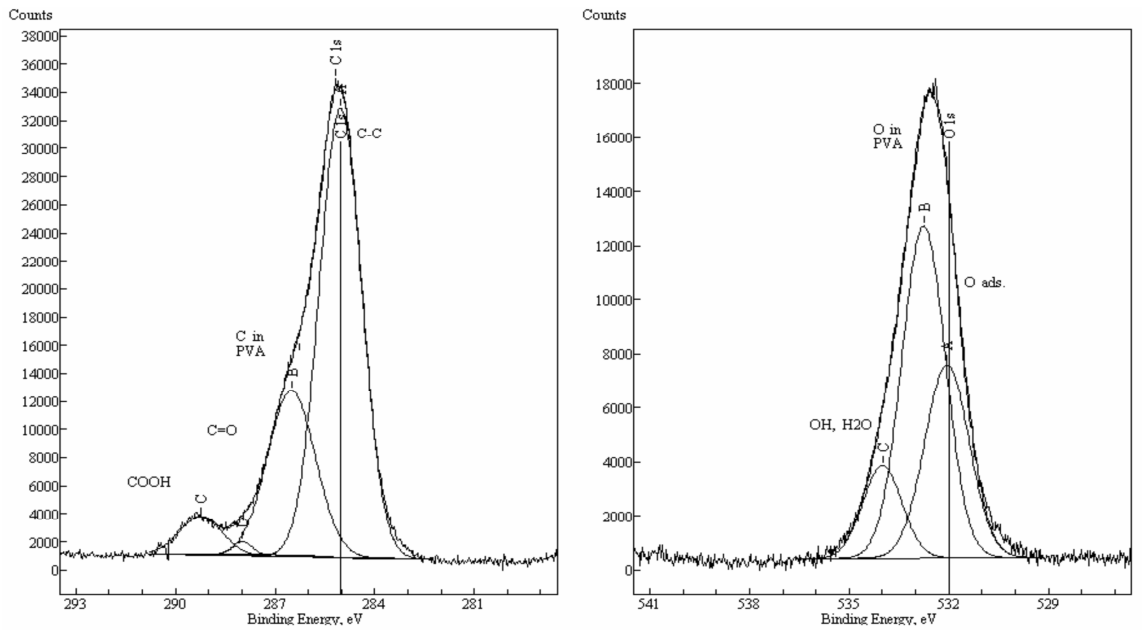

Figure 7. XPS spectra for the $\mathrm{C} 1 \mathrm{~s}$ and $\mathrm{O} 1 \mathrm{~s}$ regions of stainless steel corroded in $0.9 \%$ $\mathrm{NaCl}$ solution containing $3 \%$ poly(vinyl alcohol), at room temperature.

Table 3 presents the composition (measured by XPS) of thin layers deposited on the surface of stainless steel after corrosion in $0.9 \% \mathrm{NaCl} / \mathrm{PVA} 3 \%$ solution, at room temperature. Fig. 6 presents the high resolution XPS spectra for the C1s and $\mathrm{O} 1 \mathrm{~s}$ regions. 
Table 3. Composition of PVA layer deposited on the stainless steel surface measured by XPS.

\begin{tabular}{c|cccc}
\hline Sample/Element & $C$ & $O$ & $\mathrm{Na}$ & $\mathrm{Cl}$ \\
\hline $\begin{array}{c}\text { SS/PS/PVA 3\% } \\
\text { \%atomic }\end{array}$ & 74.2 & 25 & 0.5 & 0.3 \\
\hline
\end{tabular}

\begin{tabular}{l|ccc}
\hline Sample/Spectral line & BE/eV) & Bond & Atomic /\% \\
\hline & 285 & $\mathrm{C}-\mathrm{C}$ & 65.8 \\
SS/PS/PVA 3\% / C1s & 286.51 & $\mathrm{C}-\mathrm{O}$ from PVA & 27.6 \\
& 287.99 & $\mathrm{C}=\mathrm{O}$ & 1 \\
& 289.24 & $\mathrm{COOH}$ & 5.6 \\
\hline \multirow{3}{*}{ SS/PS/PVA 3\% / O1s } & 532 & $\mathrm{O}$ ads & 32.2 \\
& 532.75 & $\mathrm{O}$ in PVA & 54.2 \\
& 533.99 & $\mathrm{OH}, \mathrm{OH}_{2}$ & 13.6 \\
\hline
\end{tabular}

\section{Conclusions}

The results of corrosion data showed that the corrosion current density decreased and polarization resistance increased with increasing the concentration of the PVA, which indicates that this compound acts as an inhibitor, and the degree of inhibition depends on the concentration of the inhibitor. The values of inhibition efficiency increase with PVA concentration reaching an approximate value of 70 $\%$ at $3 \%$ PVA concentration.

According to the data obtained from EIS measurements it can be observed that $R_{\text {corr }}$ increases with the concentration of PVA, suggesting that the value of inhibition efficiency increases with PVA concentration. A maximum value for inhibition efficiency of $69 \%$ at $3 \%$ PVA concentration was obtained. The values of inhibition efficiency obtained from polarization curves and EIS measurements are in good agreement.

These results are consistent with those obtained by SEM and XPS analysis, which confirms that PVA forms a stable and uniform thin film and the significant feature is the adsorption. The XPS peaks of $\mathrm{Fe}, \mathrm{Cr}$ or $\mathrm{Ni}$ are not observable in the extended spectrum. This fact indicates that the substrate is completely covered.

\section{Acknowledgements}

The authors thank for the financial support to the IDEI/Grant-Program, 422 / 2008 competition.

\section{References}

1. M. Zhao, J.C. Li, Q. Jiang, Protect. Met. 39 (2003) 595-596. 10.1023/B:PROM.0000007855.73729.3b

2. S.S. Mahmoud, M.M. Ahmed, Port. Electrochim. Acta 25 (2007) 237-248. 10.4152/pea.200702237

3. H. Wang, L. Niu, Q. Hong, Su X. Wu, Feng Hua Wei, Chinese Chem. Let. 15 (2004) 486-496. 
4. P. Herrasti, P. Ocón, A. Ibáñez, E. Fatás, J. Appl. Electrochem. 33 (2003) 533-542. 10.1023/A:1024431114822

5. D.P. Le, Y.H. Yoo, J.G. Kim, S.M. Cho, Y.K. Son, Corros. Sci. 51 (2009) 330-339. 10.1016/j.corsci.2008.10.028

6. M. Finšgar, S. Fassbender, F. Nicolini, I. Milošev, Corros. Sci. 51(2009) 525-532. 10.1016/j.corsci.2008.12.006

7. Y. Jianguo, W. Lin, V. Otieno-Alego,D.P. Schweinsberg, Corros. Sci. 37 (1995) 975-983. 10.1016/0010-938X(95)00008-8

8. D. Schweinsberg, G. Hope, A. Trueman, V. Otieno-Alego, Corros. Sci. 38 (1996) 587-595. 10.1016/0010-938X(95)00148-D

9. A. Azioune, M. Marcozzi, V. Revello, J.-J. Pireaux, Surf. Interf. Anal. 39 (2007) 615-623. 10.1002/sia.2571

10. A.K. Dubey, G. Singh, Port. Electrochim. Acta 25 (2007) 221-235. 10.4152/pea.200702237

11. S. Rajendran, S.P. Sridevi, N. Anthony, A. John Amalraj, M. Sundaravadivelu, Anti-Corros. Meth. Mater. 52 (2005) 102-111. 10.1108/00035590510584816

12. S.A. Umoren, E.E. Ebenso, P.C. Okafor, O. Ogbobe, Pigment \& Resin Tech. 35 (2006) 346-354. 10.1108/03699420610711353

13. S.A. Umoren, O. Ogbobe, E.E. Ebenso, U.J. Ekpe, Pigment \& Resin Tech. 35 (2006) 284-291. 10.1108/03699420610692896

14. S.A. Umoren, E.E. Ebenso, P.C. Okafor, U.J. Ekpe, O. Ogbobe, J. Appl. Polym. Sci.103 (2007) 2810-2819. 10.1002/app.25446

15. S.A. Umoren, O. Ogbobe, P.C. Okafor, E.E. Ebenso, J. Appl. Polym. Sci. 105 (2007) 3363. 10.1002/app.26530

16. E.E. Ebenso, U.J. Ekpe, S.A. Umoren, E. Jackson, O.K. Abiola, N.C. Oforka, J. Appl. Polym. Sci.100 (2006) 2889-2901. 10.1002/app.23505

17. C.C. Negrila, C. Logofatu, R.V. Ghita, C. Cotirlan, F. Ungureanu, A.S. Manea, M.F. Lazarescu, J. Crystal Growth 310 (2008) 1576-1589. 10.1016/j.jcrysgro.2007.11.001

18. R.V. Ghita, C. Logofatu, C. Negrila, C. Cotirlan, P. Ghita, A.S. Manea, M.F. Lazarescu, Phys. Status Solid A 204 (2007)1025-1032. 10.1002/pssa.200674107

19. V. Crist, Handbooks of Monochromatic XPS Spectra, XPS International LLC, 2004. 